\title{
Double-stranded DNA Stimulates the Fibrillation of $\alpha$-Synuclein in vitro and is Associated with the Mature Fibrils: An Electron Microscopy Study
}

\section{Dmitry Cherny ${ }^{1,2}$, Wolfgang Hoyer ${ }^{1}$, Vinod Subramaniam ${ }^{3}$ and Thomas M. Jovin ${ }^{1 *}$}

${ }^{1}$ Department of Molecular Biology, Max Planck Institute for Biophysical Chemistry Am Fassberg 11, D-37077 Goettingen, Germany

${ }^{2}$ Institute of Molecular Genetics Russian Academy of Sciences Kurchatov's Square, 123182 Moscow, Russia

${ }^{3}$ Biophysical Engineering Group, Faculty of Science and Technology, University of Twente, P.O. Box 217, 7500 AE Enschede, The Netherlands

\begin{abstract}
Filamentous aggregates formed by $\alpha$-synuclein are a prominent and presumably key etiological factor in Parkinson's and other neurodegenerative diseases characterized by motor disorders. Numerous studies have demonstrated that various environmental and intracellular factors affect the fibrillation properties of $\alpha$-synuclein, e.g. by accelerating the process of assembly. Histones, the major component and constituent of chromatin, interact specifically with $\alpha$-synuclein and enhance its fibrillation significantly. Here, we report that another component of chromatin, double-stranded DNA (dsDNA), either linear or supercoiled, also interacts with wild-type $\alpha$-synuclein, leading to a significant stimulation of $\alpha$-synuclein assembly into mature fibrils characterized by a reduced lag phase. In general, the morphology of the fibrils remains unchanged in the presence of linear dsDNA. Electron microscopy reveals that DNA forms various types of complexes upon association with the fibrils at their surface without distortion of the double-helical structure. The existence of these complexes was confirmed by the electrophoresis, which also demonstrated that a fraction of the associated DNA was resistant to digestion by restriction endonucleases. Fibrils assembled from the $\alpha$-synuclein mutants A30P and A53T and the C-terminally truncated variants (encoding amino acid residues 1-108 or 1-124) also form complexes with linear dsDNA. Possible mechanisms and implications of dsDNA- $\alpha$-synuclein interactions are discussed.
\end{abstract}

(C) 2004 Elsevier Ltd. All rights reserved.

Keywords: $\alpha$-synuclein; amyloid fibril; $\beta$-sheet; DNA-fibril interaction; electron microscopy (b) a hydrophobic NAC region (residues 61-95); and (c) a very acidic $C$ terminus (residues 96-140).

$\alpha$-Synuclein is a member of the family of "natively unfolded" proteins lacking an ordered secondary structure in solution under physiological conditions. ${ }^{7}$ The functional importance of this property is unclear, although it has been established that it plays an important role in molecular recognition. ${ }^{8}$ It has been proposed that proteins or functional regions thereof can exist in three (possibly four ${ }^{8}$ ) thermodynamic states, i.e. random coil, molten globule, or ordered form and protein function can arise from any of these states or transitions between them. ${ }^{9}$ Furthermore, it was suggested that natively unfolded proteins, and in particular $\alpha$-synuclein, may exhibit distinct structural features (entirely or partly) due to binding of various ligands or varying environmental conditions. ${ }^{10-12}$ Thus, instead of adopting a
Abbreviations used: PD, Parkinson's disease; EM, electron microscopy; SPM, scanning probe microscopy; dsDNA, double-stranded DNA; ThioT, thioflavin-T.

E-mail address of the corresponding author: tjovin@gwdg.de

0022-2836/\$ - see front matter (c) 2004 Elsevier Ltd. All rights reserved. 
unique, i.e. singular, conformation, natively unfolded proteins may exist as an ensemble of alternative structures biased under the influence of environmental factors. ${ }^{9,13-16}$

The principal ordered (aggregated) state of $\alpha$-synuclein is characterized by a fibrillar morphology in which $\alpha$-synuclein (or at least its central part) adopts a $\beta$-sheet conformation. ${ }^{17,18}$ In general, the in vitro aggregates resemble material derived from disease-affected brains. ${ }^{17,19-21}$ Mature fibrils have a regular structure up to several micrometres in length, either untwisted or twisted in a right-handed or left-handed orientation, with a characteristic width/height of $\sim 10 \mathrm{~nm},{ }^{22,23}$ but the detailed structure of the mature fibrils is not known. Presumably due to the structural plasticity of $\alpha$-synuclein (and similar to other amyloid proteins), aggregated states exhibit a great morphological diversity. Thus, at low $\mathrm{pH}$ or in the presence of high concentrations of cations, $\alpha$-synuclein forms amorphous aggregates. ${ }^{24,25}$ By means of electron (EM) and scanning probe microscopy (SPM) techniques, bead-like structures with a characteristic size (height) of $2-6 \mathrm{~nm}$ were detected. ${ }^{19,26-29}$ In addition, pore-like annular structures $\sim 7-10 \mathrm{~nm}$ in diameter $26,30,31$ and tubular ${ }^{30}$ aggregates were found. Evidence exists for the formation of fibrils of smaller size (height). ${ }^{19,27}$

As a consequence of the structural flexibility of $\alpha$-synuclein, many different ligands modulate its transition to an aggregated state, generally acting to accelerate the reaction. Examples are heparin and other glycosaminoglycans, ${ }^{32}$ metal cations, ${ }^{24,25}$ pesticides, ${ }^{33}$ fatty acids and anionic detergents. ${ }^{34}$ Polyamines (putrescine, spermine, spermidine) also accelerate aggregation dramatically by virtue of their interaction with the highly negatively charged $C$ terminus of the protein. ${ }^{11,35,36}$

It has been reported that nucleic acids interact with different amyloid peptides ( $\beta$-amyloid, tau protein, prion peptides) and modulate their aggregation. ${ }^{37-45}$ In many cases a stimulatory effect of nucleic acids on aggregation (fibrillation) of the proteins was found. Nucleic acids can induce structural changes (unfolding or a transition from an $\alpha$-helical form into a $\beta$-sheet isoform) in prion peptides by forming stable complexes, which can catalyze and modulate further polymerization. ${ }^{40,43}$ However, using EM, Nandi et al. failed to detect amyloid fibrils associated with nucleic acid. ${ }^{40}$ Aggregated $\beta$-amyloid peptides $A \beta(1-40)$ and A $\beta(25-35)$ associate with double-stranded DNA (dsDNA), although no interaction was detected with the monomeric forms. ${ }^{37}$ In addition, $\beta$-amyloid peptide $A \beta(25-35)$ can convert a supercoiled DNA into an open circle in the presence of ferrous ions. ${ }^{38}$ In contrast to the $\beta$-amyloid peptides, the aggregation process of $\alpha$-synuclein has been regarded as unmodulated by nucleic acids (tRNA, total RNA, dsDNA). ${ }^{32}$

Here, we present evidence for the interaction of wild-type $\alpha$-synuclein, A30P and A53T mutants, and $C$ terminus-truncated fragments with dsDNA.
The fibrillation of wild-type $\alpha$-synuclein is notably accelerated by linear dsDNA, and mature fibrils remain associated with the DNA. We hypothesize that dsDNA serves as a template facilitating the assembly of $\alpha$-synuclein into mature fibrils.

\section{Results}

Preliminary EM experiments indicated that incubation of wild-type $\alpha$-synuclein with dsDNA led to the formation of regular mature fibrils with which DNA remained associated. In order to analyze this phenomenon in detail we monitored the kinetics of $\alpha$-synuclein aggregation by means of a thioflavin- $T$ (ThioT) binding assay. ThioT interacts with aggregated $\alpha$-synuclein, leading to a significant increase in fluorescence intensity. In the absence of DNA the kinetics were much slower relative to that in the presence of DNA (Figure 1A). The experimental data were analyzed using equation $(1):^{11}$

$$
\alpha(t)=\frac{1-\exp ^{-k_{\mathrm{app}} t}}{1+a \exp ^{-k_{\mathrm{app}} t}}
$$

where $\alpha(t)$ is the fraction of aggregated $\alpha$-synuclein, $k_{\text {app }}$ is the effective rate constant of fibrillation and $a$ is a parameter reflecting the nucleation processes determined mainly by the dissociation constant of the nucleation center. According to this model, the time, $t_{1 / 2}$, needed to reach the midpoint of the reaction, i.e. $\alpha=0.5$, is given by $t_{1 / 2} \approx \ln (a) / k_{\mathrm{app}}$. It is seen that $k_{\mathrm{app}}$ remained unchanged (within experimental errors), but that $t_{1 / 2}$ decreased significantly in the presence of DNA (Figure 1B).

A small initial fluorescence signal for the incubations with DNA could be attributed to the interaction of ThioT with free DNA. Indeed, in the absence of protein (but in the presence of DNA) the fluorescence exceeded that of ThioT alone and remained stable for several days (not shown), indicating the formation of a direct dye-DNA complex. ${ }^{42,46}$ The gradual decrease of the signal to $\sim$ zero at $\sim 25$ hours most probably reflected the progressive loss of freely accessible DNA, while for times $>25$ hours the fluorescence signal arose from the interaction of ThioT with the aggregated $\alpha$-synuclein.

The mature fibrils assembled from wild-type $\alpha$-synuclein (at $100 \mu \mathrm{M}$ ) in the absence of DNA were long and straight with a width of $\sim 10 \mathrm{~nm}$ (Figure 2A). When linear dsDNA $(30 \mu \mathrm{g} / \mathrm{ml})$ was added to the incubation mixture from the outset, short and long mature fibrils of similar width were observed. However, almost all DNA molecules were associated with the fibrils, forming various types of complexes (Figure 3). The DNA was clearly visible on dark-field images as thin curved threads crossing the fibrils at different angles. It was often impossible to trace the entire contour of the DNA molecule, as the latter remained associated closely with the fibril body. The samples for EM imaging were stained with uranyl acetate, which interacts 
A

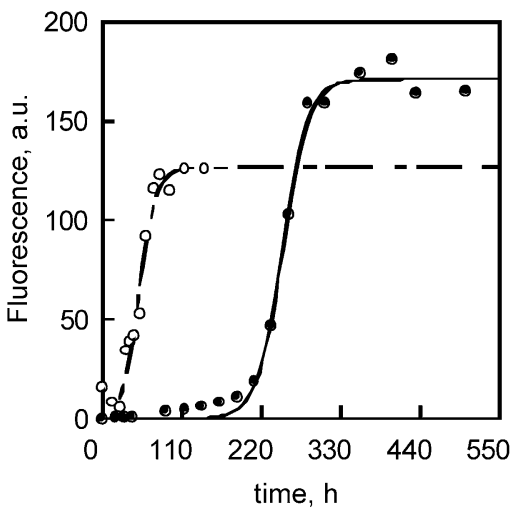

B

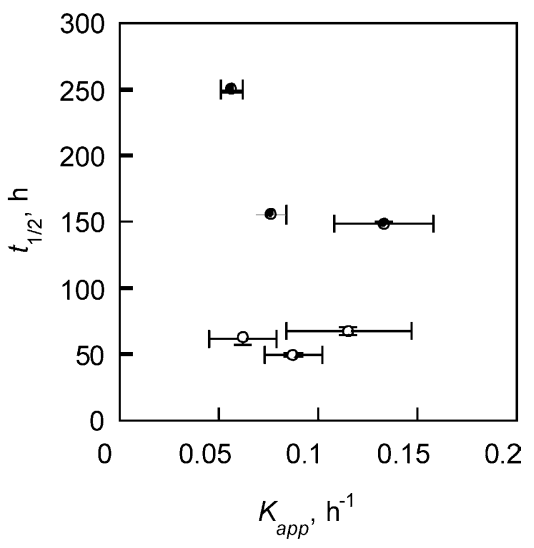

Figure 1. Kinetics of $\alpha$-synuclein aggregation. A, Kinetics of $\alpha$ synuclein $(100 \mu \mathrm{M})$ fibrillation upon incubation without (O) and with $(O)$ salmon sperm DNA $(30 \mu \mathrm{g} / \mathrm{ml})$ at $37^{\circ} \mathrm{C}$ with constant stirring at $\mathrm{pH} 7.5$. At the indicated times, aliquots were withdrawn, mixed with ThioT and fluorescence was measured (excitation $446 \mathrm{~nm}$, emission $480 \mathrm{~nm}$ ). The continuous and broken lines represent fits to equation (1) according to Fernandez et al. ${ }^{11}$ Non-zero values of fluorescence for the incubation with DNA for $t<25$ hours were not considered for the fits. B, The graph represents datasets $\left(k_{\mathrm{app}}\right.$ and $t_{1 / 2}$ ) calculated from corresponding fits to the $\alpha$-synuclein fibrillation kinetics in the absence $(\mathcal{O})$ and in the presence $(O)$ of DNA obtained from three runs for each reaction condition.

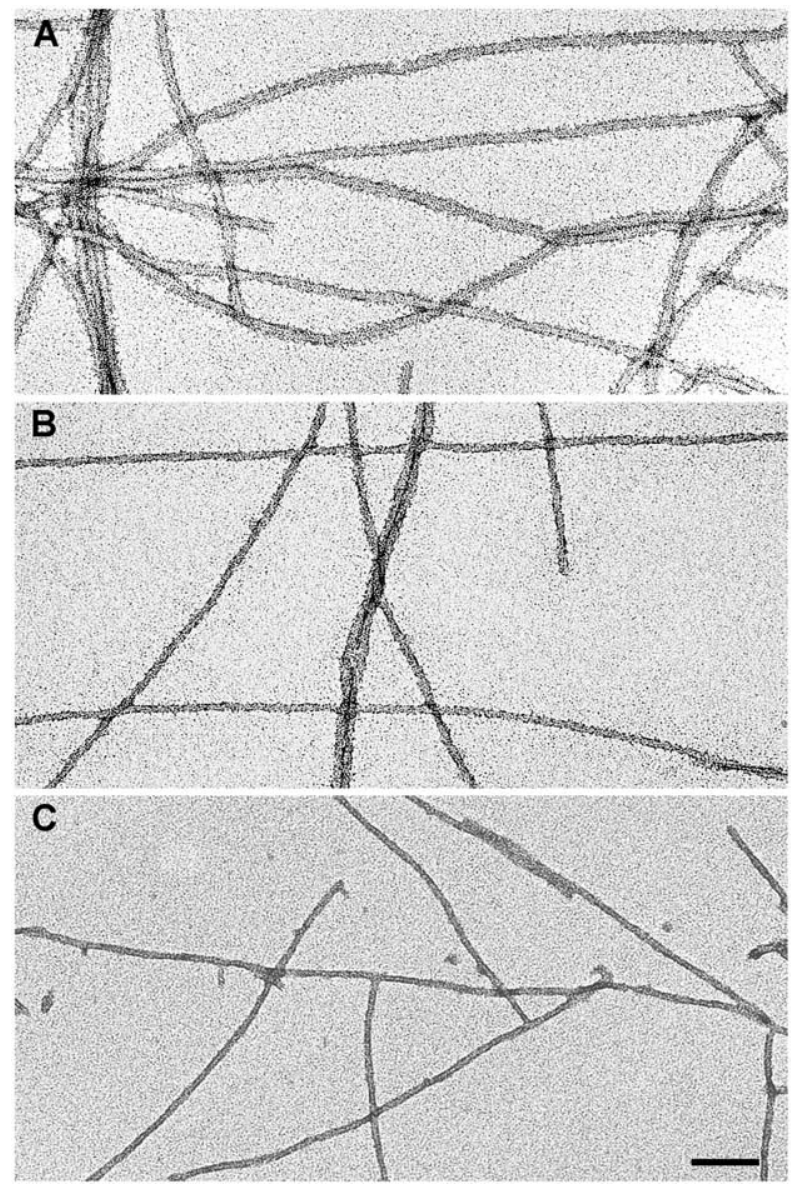

Figure 2. Formation of mature fibrils. EM images of $\alpha$ synuclein fibrils formed by the wild-type (A), A53T mutant (B) and A30P mutant (C) after incubation at $37^{\circ} \mathrm{C}$ for several (three to five) days. The concentration of the protein was $100 \mu \mathrm{M}$. Images were acquired in a brightfield mode. A, Image of negatively stained sample. B and C, Images of positively stained samples. The scale bar represents $100 \mathrm{~nm}$.

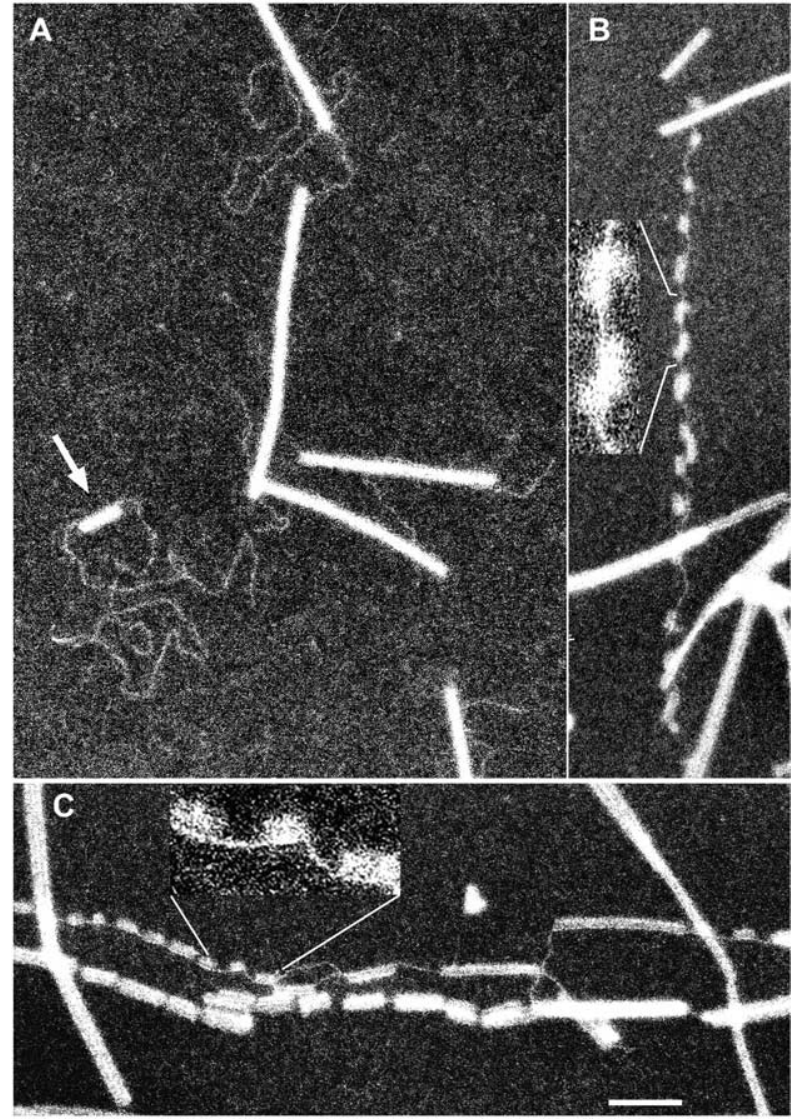

Figure 3. Assembly of wild-type $\alpha$-synuclein into fibrils in the presence of linear DNA. EM images of various types of DNA-fibril complexes formed after the incubation of pPGM1/ScaI DNA (30 $\mu \mathrm{g} / \mathrm{ml})$ with $\alpha$-synuclein $(100 \mu \mathrm{M})$ at $37^{\circ} \mathrm{C}$ for several (three to five) days. Images were acquired in an angular dark-field mode. The arrow on A indicates the complex used for length measurements. The scale bar represents $100 \mathrm{~nm}$. 
both with DNA phosphate groups and $\alpha$-synuclein amino acid side groups, thereby obscuring the DNA within the complexes.

The most unambiguous evidence for the association of DNA with fibrils were the DNA molecules emerging from the ends of fibrils (short or long) and apparently joining fibrils via their termini. A small fraction of fibrils (a small percentage of the total fibril length) linked in this manner formed long trains (Figure 3B and C). Interestingly, the fibrils in this case were usually short, in the range of $\sim 15$ $50 \mathrm{~nm}$, with an inter-fibrillar separation of $\sim 10$ $40 \mathrm{~nm}$ (mean $\sim 20 \mathrm{~nm}$ ). As shown in the insets in Figure $3 \mathrm{~B}$ and $\mathrm{C}$, DNA was observed as a thin thread running either along the fibril axis or the fibril border. This observation confirmed that DNA was associated with the fibril surface.

Length measurements of DNA associated with fibrils (indicated by arrowheads in Figure 3A), i.e. the length of visible DNA tails and the distance over which DNA is associated with the fibril surface, yielded values compatible with the full DNA length (regardless of the length of the fibril-associated segment), indicating the absence of significant distortions of the DNA backbone.

Examination by EM of the incubations with various DNA and $\alpha$-synuclein concentrations at intermediate times, i.e. significantly shorter than required for the formation of mature fibrils, showed correlations between the process of fibril growth and association of DNA with the fibrils. At short times corresponding to the absence of the fluorescence signal (Figure 1), no fibrils were detected, whereas DNA remained in its unperturbed state, apparently without bound proteins. In contrast, at times corresponding to an increase in ThioT signal, short fibrils similar in width to mature fibrils were usually detected, and the DNA molecules (all or a fraction, depending on initial concentrations of DNA and protein) were associated with the fibrils. At still longer times the concentration of the fibrils on the EM support, alone and DNA-associated, increased progressively. The DNA-fibril complexes exhibited a similar structure, regardless of the incubation time (Figures 2 and 3).

Association of linear DNA with mature fibrils was confirmed by gel electrophoresis. At a DNA concentration of $50 \mu \mathrm{g} / \mathrm{ml}$ and $20 \mu \mathrm{M}$ wild-type $\alpha$-synuclein, $>55 \%$ of pPGM1/EcoRI DNA did not enter the gel, whereas the rest migrated as naked linear DNA (Figure 4, lanes 1 and 2); this relationship was confirmed by parallel EM examination (not shown). Furthermore, digestion with a large excess of ScaI restriction endonuclease, with subsequent treatment with proteinase $\mathrm{K}$ in the presence of $1 \%(\mathrm{w} / \mathrm{v})$ SDS, showed that $<10 \%$ of DNA was resistant to cleavage. The remainder of the DNA migrated as two distinct bands with mobilities corresponding to the fragment lengths predicted from the positions of the EcoRI and ScaI recognition sites (Figure 4, lanes 3 and 4). The fractional resistance of the fibril-associated DNA to endonuclease digestion presumably reflected a

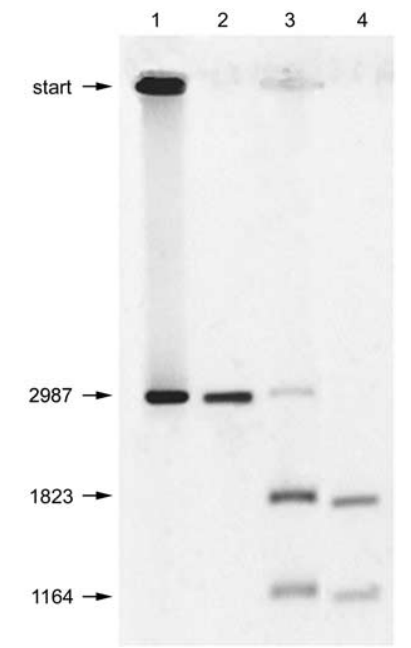

Figure 4. Association of wild-type $\alpha$-synuclein with dsDNA monitored by gel electrophoresis. The experiments were performed by incubation of pPGM1/EcoRI DNA $(50 \mu \mathrm{g} / \mathrm{ml})$ with wild-type $\alpha$-synuclein $(20 \mu \mathrm{M})$ for more than five days, then an aliquot was withdrawn and loaded onto a gel (lane 1 ); $>55 \%$ of DNA did not enter the gel, whereas the rest migrated as naked pPGM1/EcoRI DNA (reference lane 2). An aliquot from the same mixture was withdrawn and incubated with a large excess of ScaI with subsequent treatment with proteinase K/SDS (see Materials and Methods) and loaded onto lane $3 ;<10 \%$ of DNA was not cut, as opposed to $100 \%$ in the case of noncomplexed DNA (lane 4). The numbers on the left indicate the size of the DNA fragments (in bp).

random positioning of the fibrils along the DNA sequence and variability in the length of the interaction region.

$\alpha$-Synuclein fibrils assembled in the presence of supercoiled DNA were morphologically similar to those obtained in the absence of DNA or in the presence of linear DNA, although the major part of scDNA was associated with the fibrils in a manner similar to that with the linear counterpart (not shown).

The association of DNA with $\alpha$-synuclein fibrils was not limited to the wild-type protein. Mutants $\mathrm{A} 53 \mathrm{~T}$ and $\mathrm{A} 30 \mathrm{P}^{47,48}$ formed long regular fibrils (twisted and untwisted) $\sim 10 \mathrm{~nm}$ in width (Figure 2B and $\mathrm{C}$, respectively) with kinetic parameters ( $a$ and $t_{1 / 2}$ ) similar to those of wild-type protein. ${ }^{12}$ In the presence of linear dsDNA, similar fibrils were formed, although again a major part of the DNA was associated with fibrils in a manner similar to that for wild-type $\alpha$-synuclein (Figure 5A-D, respectively). Long trains (similar to those formed by wild-type) consisting of short fibrils end-linked by DNA were present as well. In a few instances, long individual fibrils were associated side-by-side, an interaction apparently mediated by the dsDNA (Figure 5C).

$\alpha$-Synuclein lacking the last 32 or $16 \mathrm{C}$-terminal amino acid residues also formed fibrils (Figure 6A 

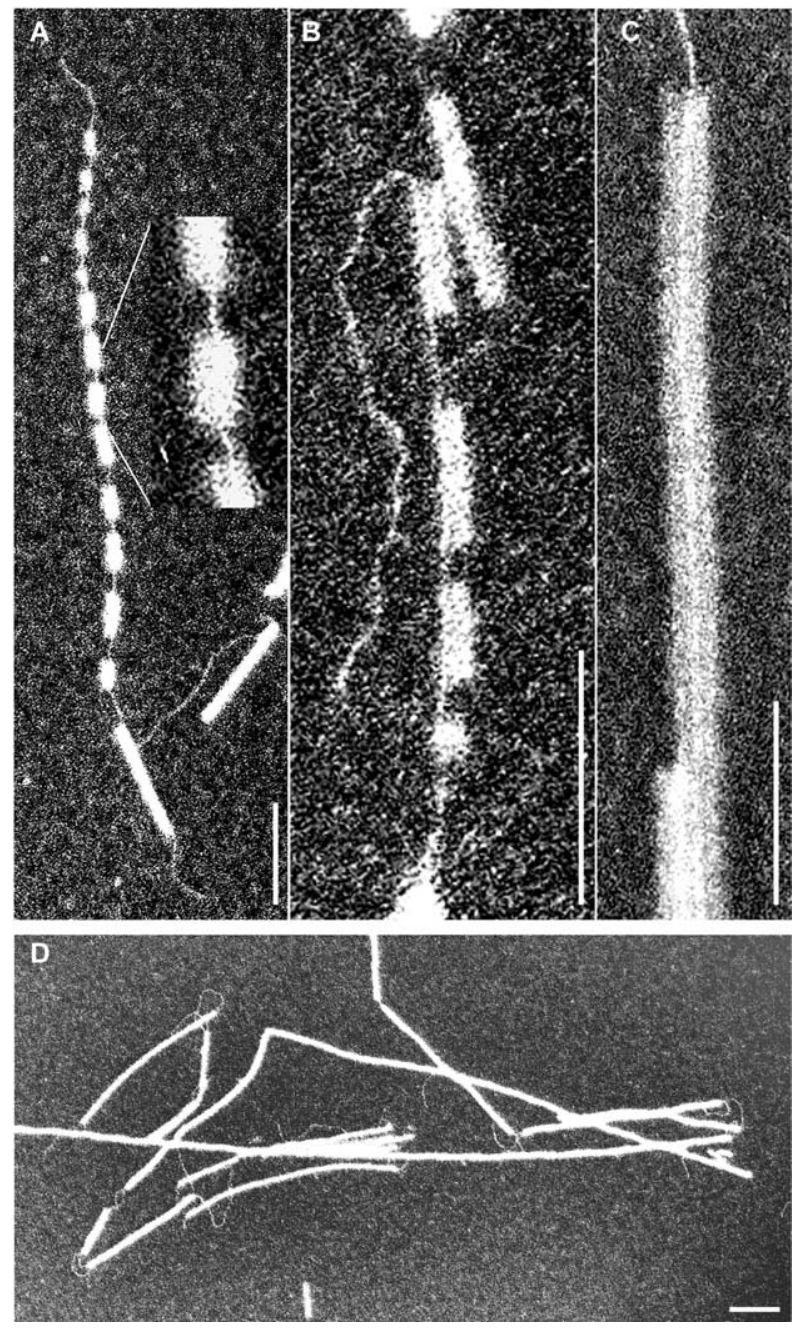

Figure 5. Assembly of A53T and A30P $\alpha$-synuclein into fibrils in the presence of linear DNA. EM images of DNAfibril complexes formed after the incubation of pPGM1/ScaI DNA $(30 \mu \mathrm{g} / \mathrm{ml})$ with A53T mutant (A-C) or A30P mutant (D) at $37^{\circ} \mathrm{C}$ for several (three to five) days. The concentration of protein was $100 \mu \mathrm{M}$. Images were acquired in an angular dark-field mode. The scale bars represent $100 \mathrm{~nm}$.

and $C$, respectively) with kinetic profiles qualitatively similar to those of the wild-type protein, although with faster rates. ${ }^{12}$ The morphology of individual fibrils was similar to those formed by the wild-type protein but the distribution of the fibrils on the surface of the EM grid was very irregular, most probably due to a tendency to coalesce. In the presence of DNA, fibrils, $\sim 10 \mathrm{~nm}$ in width and slightly shorter, were distributed irregularly over the EM carbon film. Free DNA was almost absent. Instead, the DNA was either associated with individual fibrils (Figure 6B) or within large nets consisting of numerous relatively short fibrils, apparently linked by a large number of DNA molecules (Figure 6D). Fibrils joined into trains at their termini were clearly visible inside these large aggregates.
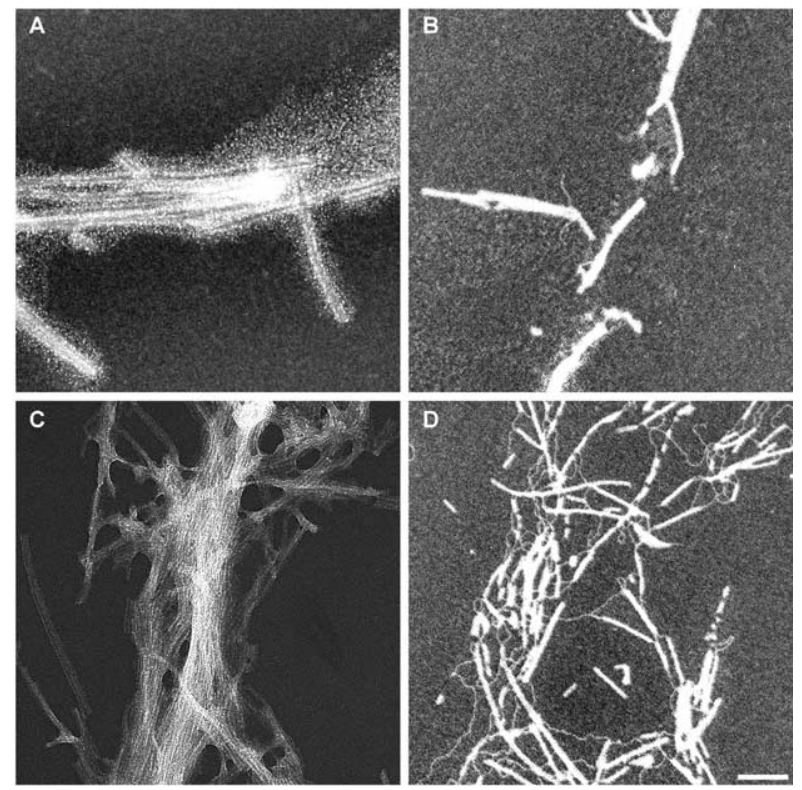

Figure 6. Assembly of $C$ terminus truncated $\alpha$ synuclein into fibrils in the presence of linear DNA. EM images of fibrils assembled by 1-108 and 1-124 peptides $(100 \mu \mathrm{M}$, respectively) in the absence (A and C, respectively) and in the presence of pPGM1/ScaI DNA (B and D, respectively) after the incubation at $37^{\circ} \mathrm{C}$ for several (three to five) days. Images were acquired in an angular dark-field mode. The scale bar represents $100 \mathrm{~nm}$.

The concurrent incubation of dsDNA and $\alpha$-synuclein was not a prerequisite for DNA association with the fibrils. Addition of dsDNA to preformed fibrils and a relatively short subsequent incubation (without stirring) at $37^{\circ} \mathrm{C}$ for one to three hours also led to the formation of complexes without apparent changes of fibril morphology. The yield of complexes was lower compared to the incubations in which dsDNA was present from the very beginning, i.e. $\sim 40-50 \%$ of linear and $\sim 30-40 \%$ of supercoiled molecules were found associated with fibrils and these fractions did not increase upon extended incubation (not shown). The structure of complexes formed by linear DNA (Figure 7A) or supercoiled DNA (Figure 7B) was very similar to that described above. However, despite the fact that DNA molecules were associated with the termini of the fibrils, train formation was not detected.

\section{Discussion}

We show here that dsDNA accelerates the assembly of $\alpha$-synuclein into fibrils and remains associated with the fibrils produced. We hypothesize that dsDNA may act as a template and/or nucleation catalyst that facilitates assembly of $\alpha$-synuclein into fibrils. There are several lines of evidence supporting this conjecture: (i) a significant decrease in the half-time $\left(t_{1 / 2}\right)$ of the aggregation 

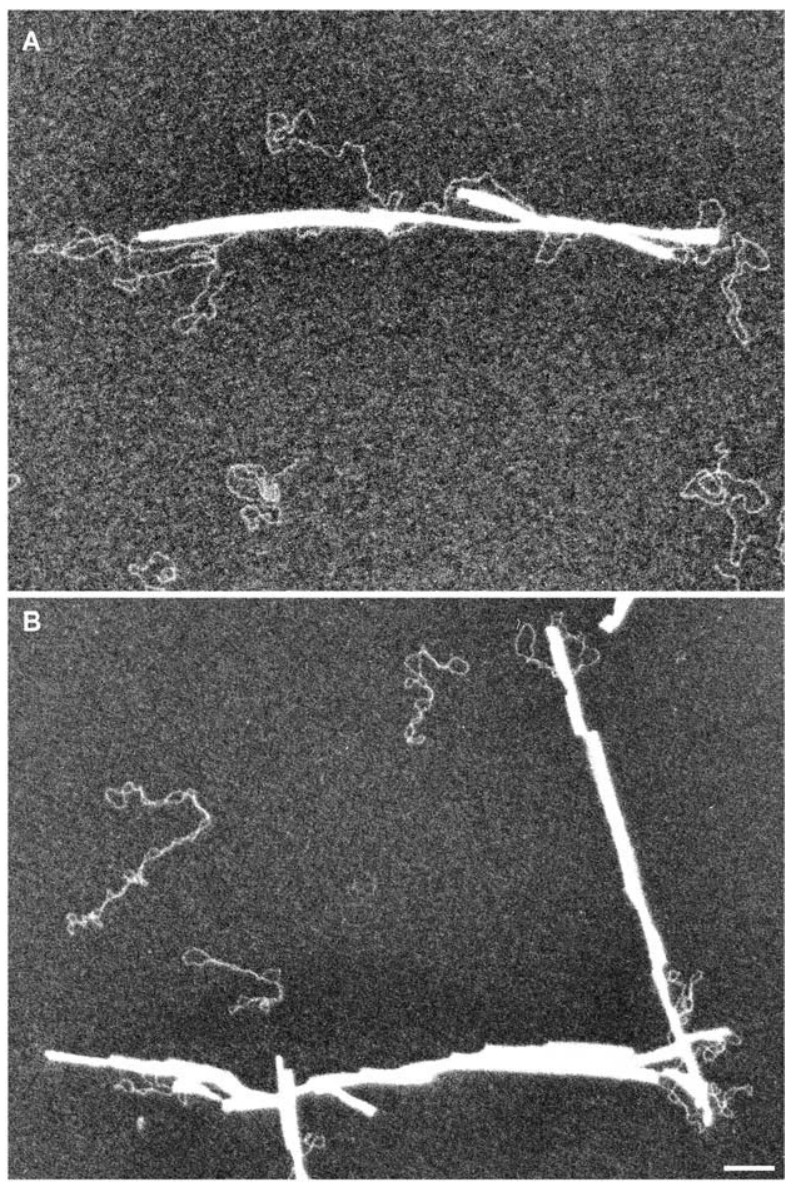

Figure 7. Association of dsDNA with preformed fibrils. EM images of the samples obtained after the incubation of pPGM1/ScaI (A) or sc pPGM1 (B) DNA with preformed fibrils assembled from the wild-type $\alpha$-synuclein (see Figure 2A). Images were acquired in an angular dark-field mode. The scale bar represents $100 \mathrm{~nm}$.

compared to the reaction performed in the absence of dsDNA; (ii) invariance of the effective rate constant of fibrillation in the presence or absence of DNA; (iii) association of DNA with the surface of the fibrils; (iv) similarity of fibril morphology grown in the absence and in the presence of dsDNA; (v) absence of apparent modulations of the DNA backbone.

A plausible scenario for the DNA stimulatory effect is the following: In solution, protein molecules, presented mainly as monomers, ${ }^{49}$ interact electrostatically with DNA phosphate groups. DNA interacts most likely with the positively charged lysine side-chains located primarily in the N-terminal part and the central region of the protein; interaction with the negatively charged $C$ terminus is unlikely. These electrostatic interactions potentially (i) lead to the formation of nonsequence-specific complexes with DNA, and (ii) increase the local concentration of protein. Both effects, acting in a concerted manner, dramatically increase the probability of dimer formation, the critical nucleation structure needed for fibril growth. ${ }^{11,49}$ We cannot exclude the possibility of specific folding of DNA-bound protein monomers localized in close register, also leading either to formation of nucleation centers (dimers) or direct assembly of proteins into filaments or both. The latter possibility is very likely, as the DNA molecules (all or in part depending on the initial concentrations of DNA and/or protein in solution) finally associate with the fibrils. This scenario is consistent with stimulation of $\alpha$-synuclein fibrillation detected by polyanions, ${ }^{32}$ anionic detergents, ${ }^{34}$ and negatively charged mica surface, ${ }^{29}$ although the authors observed aggregates of quite different morphologies, probably due to the structural plasticity of the protein. The appearance of the structures shown in Figure 5C, in which long individual fibrils were associated side-by-side in a process mediated by the dsDNA, may be indicative of a preferential position of positive and negative charges on the fibril surface. The association of DNA with the fibrils is relatively strong, conferring upon the DNA a resistance to digestion by restriction endonuclease.

In mature fibrils, only the central part of the polypeptide chain ( $\sim 30$ to $\sim 100$ residues) is highly ordered and specifically folded, whereas the $\mathrm{N}$ terminus is structurally heterogeneous, ${ }^{18}$ implying a localization close to the fibril surface. Thus, accessible, positively charged lysine side-chains of the $\mathrm{N}$ terminus may be recruited by DNA (linear or supercoiled) for its interaction with preformed fibrils. However, the significant difference in the yield of complexes depending on when DNA was added to the incubation mixture is indicative of the involvement of additional factors accounting for the interaction between DNA and $\alpha$-synuclein. In this respect, the interaction of DNA with $\beta$-strands of fibrils is unlikely, as usually in DNA-protein complexes, $\beta$-strands (in N-to-C direction) either cross or follow the DNA grooves. ${ }^{50}$ When a $\beta$-strand crosses the minor groove, a significant distortion of DNA helix is observed; when a $\beta$-strand follows the major groove, the angle between $\beta$-strand and DNA axis should be fixed $\left(\sim 30^{\circ}\right)$. Since the $\beta$-strands exhibit an approximately perpendicular orientation with respect to the fibril axis, ${ }^{17}$ our observations do not support either of these predictions.

The $C$ terminus within $\alpha$-synuclein fibrils is unstructured, ${ }^{18}$ but recent NMR data demonstrate the presence of a well-defined binding interface in its native state in solution. ${ }^{11}$ Some of the $\mathrm{C}$ termini are located on the surface of mature fibrils. ${ }^{17,51}$ Repulsion between these solution-exposed, highly negatively charged $C$ termini likely prevents coalescence of the mature fibrils, thus leading to the images of non-interacting fibrils. Fibrils assembled from the $C$ terminus-truncated $\alpha$-synuclein were morphologically similar to those formed from the wild-type protein, but they exhibited a strong tendency for aggregation, presumably due to a lack of repulsive forces. However, DNA was still 
associated with the fibrils and probably associated via interactions (at least in part) with the N-terminal residues.

The integration of fibrils into trains also supports our conjecture about dsDNA acting as a template facilitating the processes of nucleation and fibril assembly. The relatively short length of the segments constituting the trains, i.e. 15-50 nm, may be accounted for, in part, by high dsDNA flexibility relative to that of mature fibrils and leading to a structural instability of DNA-associated fibrils above a certain length limit. The relatively small yield of complexes obtained in incubations with DNA added $a$ posteriori, i.e. after the formation of mature fibrils was completed, supports our conjecture that DNA flexibility is a factor that partially prevents the formation of complexes by virtue of electrostatic interactions over distances comparable to the DNA persistence length, i.e. $\sim 50 \mathrm{~nm}$.

The fibrils assembled from A30P and A53T mutants ${ }^{47,48}$ morphologically resembled those formed with the wild-type protein but exhibited a helical twist, which was in agreement with EM and X-ray data. ${ }^{17}$ It is tempting to speculate that the $\mathrm{N}$ terminus of A30P or A53T assembled fibrils was also located close to the fibril surface. Thus, the association of DNA with these proteins and with assembled fibrils would be quite feasible.

The absence of a modulation effect of nucleic acids and dsDNA, in particular, on $\alpha$-synuclein fibrillation reported by Cohlberg et al. ${ }^{32}$ most probably arises from the interaction of ThioT with the dsDNA, ${ }^{42,46}$ inasmuch as the authors analyzed the reactions of fibrillation in an assay containing 10-20 $\mu \mathrm{M}$ ThioT. Our data provide the first experimental evidence documenting the involvement of dsDNA in a process of $\alpha$-synuclein fibrillation.

The significance of DNA-induced $\alpha$-synuclein fibrillation and DNA association with the fibrils is unclear at the present time. In the cell, $\alpha$-synuclein interacts and/or co-localizes with various proteins that are components of signaling pathways or are potentially required for regulation of $\alpha$-synuclein functions. $^{4,52}$ In general, aggregated $\alpha$-synuclein is localized in the brain stem and cortical Lewy bodies and Lewy neurites are located in cytoplasm. Recent studies show that $\alpha$-synuclein is present in neuronal nuclear inclusions and neuritis in multiple system atrophy in the form of bundled filaments 10-20 nm in diameter. ${ }^{53}$ However, the latter are not membrane-bound and are separated from chromatin aggregates. In this respect, Goers et al. ${ }^{54}$ provided evidence for the co-localization of $\alpha$-synuclein with histones in the nuclei of nigral neurons from mice exposed to a toxic insult. The authors measured the stoichiometry of the histone: $\alpha$-synuclein complex $(2: 1)$ and showed that histones stimulate $\alpha$-synuclein fibrillation in vitro.

The interaction of dsDNA with $\alpha$-synuclein and its stimulation of assembly into mature fibrils indicate that both components of chromatin may have a significant effect on nuclear-translocated $\alpha$-synuclein functioning. In particular, $\alpha$-synuclein may interact with histone-free, transcriptionally active DNA segments and therefore lead to a decreased transcriptional activity of some genes responding to environmental stimuli. An opposite effect, i.e. stimulation of transcription by $\alpha$-synuclein sequestering histones, has been proposed by Goers et al. ${ }^{54}$ Taken together, our findings and those of Goers et al. provide evidence that the interaction(s) of $\alpha$-synuclein with DNA and histones might serve to regulate gene expression.

Due to structural plasticity of $\alpha$-synuclein and its disposition to aggregation under the influence of numerous cellular factors, the mechanisms maintaining $\alpha$-synuclein in a soluble form and preventing its fibrillation are of primary importance. In brain cells, the synucleins ( $\alpha$ and $\beta$ ) account for $\sim 0.1-0.2 \%$ of the total protein, ${ }^{1,55}$ corresponding to $\sim 2 \times 10^{7}-4 \times 10^{7}$ synuclein molecules per cell. The mass density of the fibrils can be estimated as 5-10 protein molecules/nm of fibril length depending on a physical model of filament structure, e.g. the intertwining of multiple protofilaments $^{23,56}$ or a single $10 \mathrm{~nm}$ filament. ${ }^{18,23}$ The latter would correspond to $\sim 5 \times 10^{3}-1 \times 10^{4}$ protein molecules per $1 \mu \mathrm{m}$ of fibril length. Assuming that the fibrils can be packed tightly into a cube $1 \mu \mathrm{m}$ on a side, the number of $\alpha$-synuclein molecules would be $\sim 10^{8}$, a value close to the estimated total number of molecules in the cell. It is worth noting that the size of Lewy bodies is in the range of $\sim 5-15 \mu \mathrm{m}^{3}$, implying that they may contain almost all of the $\alpha$-synuclein molecules present in the cell. Furthermore, in a cell with a volume of $\sim 2-4 \mathrm{pl}$, the average synuclein concentration is $\sim 4-40 \mu \mathrm{M}$, a value close to the critical concentration sufficient for fibril growth. ${ }^{57}$ Assuming that all the $\alpha$-synuclein molecules are concentrated in the nucleus, the concentration would be about five times higher, i.e. 20$200 \mu \mathrm{M}$. Neuronal nuclear inclusions are different in size and shape, with characteristic sizes of a few tenths of a micrometre or close to a micrometre, ${ }^{53}$ thus potentially accounting for a significant fraction of the total amount of $\alpha$-synuclein in a cell. These considerations indicate that minute variations in local synuclein concentration or the presence of factors enhancing its fibrillation, e.g. DNA or histones, may stimulate significantly the aggregation of $\alpha$-synuclein into fibrillar structures, implying that effective mechanisms preventing unnecessary or occasional conversion of a soluble $\alpha$-synuclein into insoluble isoforms must exist in both the cytoplasm and the nucleus.

\section{Materials and Methods}

\section{Expression and purification of proteins}

Recombinant human wild-type, A53T and A30P $\alpha$-synuclein were expressed and purified as described, ${ }^{25}$ using plasmid pT7-7 encoding for the proteins (courtesy of the Lansbury laboratory, Harvard Medical School, 
Cambridge, MA). The carboxy-terminally truncated $\alpha$-synuclein fragments $\operatorname{syn}(1-108)$ and $\operatorname{syn}(1-124)$ were amplified by PCR from full-length wild-type $\alpha$-synuclein and subcloned into pT7-7. The sequence was confirmed by DNA sequencing. Expression and purification of the truncated proteins was performed essentially as described for full-length $\alpha$-synuclein. ${ }^{25}$ The identity of all proteins was verified by mass spectroscopy. Protein concentrations were determined with the bicinchoninic acid (BCA) assay and validated by absorbance measurements at $275 \mathrm{~nm}$ using an extinction coefficient of $1400 \mathrm{M}^{-1} \mathrm{~cm}^{-1}$ per tyrosine residue.

\section{DNA}

Salmon sperm DNA (Sigma) was dissolved in $10 \mathrm{mM}$ Tris-HCl (pH 7.5), $50 \mathrm{mM} \mathrm{NaCl}$. Supercoiled pPGM1 (a derivative of pBluescript SK II+DNA, 3000 bp) DNA was obtained as described. ${ }^{58}$ pPGM1 digested with ScaI was extracted with phenol and precipitated with ethanol. All DNA samples were finally purified by using a Superose 12 column (SMART system, Amersham Pharmacia Biotech, Sweden) equilibrated with $10 \mathrm{mM}$ Tris- $\mathrm{HCl}$ (pH 7.5), $50 \mathrm{mM} \mathrm{NaCl}$.

\section{In vitro fibril formation}

Fibrils were generated by incubation of a solution $(200-300 \mu \mathrm{l})$ containing protein at a concentration of $20-100 \mu \mathrm{M}$ in $25 \mathrm{mM}$ Tris- $\mathrm{HCl}(\mathrm{pH}$ 7.5) and DNA (where indicated). Incubation was carried out at $37^{\circ} \mathrm{C}$ in glass vials under constant stirring with micro Tefloncoated stir bars using a multiple stirrer Telesystem HP15S (Variomag) at $300 \mathrm{rpm}$. For kinetic measurements wildtype $\alpha$-synuclein $(100 \mu \mathrm{M})$ was incubated with salmon sperm DNA $(30 \mu \mathrm{g} / \mathrm{ml})$. For EM experiments, pPGM1/ScaI or pPGM1/EcoRI DNA was added to a final concentration of $20-50 \mu \mathrm{g} / \mathrm{ml}$ and incubations were continued until the formation of mature fibrils occurred (several days). Aliquots were withdrawn at different times (approximately every six to ten hours) and used for EM sample preparation. For the experiments with DNA and mature fibrils, pPGM1/ScaI or sc pPGM1 DNA was added to a final concentration of $\sim 35 \mu \mathrm{g} / \mathrm{ml}$ and the incubation continued for one to three hours at $37^{\circ} \mathrm{C}$ without stirring. For gel electrophoresis experiments, pPGM1/EcoRI DNA $(50 \mu \mathrm{g} / \mathrm{ml})$ was incubated with wild-type $\alpha$-synuclein $(20 \mu \mathrm{g} / \mathrm{ml})$ for at least five days.

\section{Kinetics of fibril formation}

Kinetics of fibril formation was monitored with the ThioT assay as described. ${ }^{25}$ Briefly, $7.5 \mu 1$ aliquots were withdrawn from incubation mixtures at various times and added to $2.0 \mathrm{ml}$ of $5 \mu \mathrm{M}$ ThioT in $50 \mathrm{mM}$ Na-glycine ( $\mathrm{pH}$ 8.2). The final concentration of protein was $0.37 \mu \mathrm{M}$. Fluorescence measurements were carried out on a Cary Eclipse spectrofluorimeter using $3.5 \mathrm{ml}$ quartz cuvettes (Hellma) with a $1 \mathrm{~cm}$ light-path as described. ${ }^{25}$ Fluorescence emission spectra were recorded from $465 \mathrm{~nm}$ to $600 \mathrm{~nm}$, using excitation at $446 \mathrm{~nm}$, an integration time of 0.1 second, and both excitation and emission bandwidths of $10 \mathrm{~nm}$.

\section{Gel electrophoresis}

After the formation of fibrils was completed, an aliquot (10 $\mu$ l containing $0.5 \mu \mathrm{g}$ of DNA) was withdrawn from the incubation mixture, supplemented with the ScaI restriction endonuclease (20 units) and the corresponding buffer and incubated for 2.5 hours at $37^{\circ} \mathrm{C}$. Proteinase $\mathrm{K}$ $(100 \mu \mathrm{g} / \mathrm{ml})$ and SDS $(1 \%, \mathrm{w} / \mathrm{v})$ were added, and incubation was continued for two hours at $37^{\circ} \mathrm{C}$. Gel electrophoresis was performed in $1 \%(\mathrm{w} / \mathrm{v})$ agarose in $40 \mathrm{mM}$ Tris-acetate, $1 \mathrm{mM}$ EDTA ( $\mathrm{pH} 8.0$ ) at $3.5 \mathrm{~V} / \mathrm{cm}$ for four hours.

\section{Electron microscopy}

Samples for EM examination were prepared as described. ${ }^{25}$ An aliquot was withdrawn from the mixture at different times (indicated in the text and Figure legends) and diluted 50-100-fold in $10 \mathrm{mM}$ Tris- $\mathrm{HCl}$ (pH 7.5), $10 \mathrm{mM} \mathrm{NaCl}$, and placed on a glow-discharged carbon film attached to an EM grid. After about one minute of adsorption the grids were rinsed with a few drops of $2 \%(\mathrm{w} / \mathrm{v})$ aqueous uranyl acetate, blotted with filter-paper, and dried. The samples were examined with a Philips CM12 electron microscope (Philips, The Netherlands) either in bright-field or angular dark-field modes (as indicated in the Figure legends). The negatives were scanned with a DuoScan T2500 scanner (Agfa, Germany) at $1200 \mathrm{dpi}$. Measurements of the micrographs were carried out with the Windows version of NIH Image (Scion Corporation). For printing, images were flattened using a high-pass filter with a radius of 250 pixels and subsequently adjusted for contrast/brightness using Adobe Photoshop.

\section{References}

1. Spillantini, M. G. \& Goedert, M. (2000). The $\alpha$-synucleinopathies: Parkinson's disease, dementia with Lewy bodies, and multiple system atrophy. Ann. N Y Acad. Sci. 920, 16-27.

2. Baba, M., Nakajo, S., Tu, P. H., Tomita, T., Nakaya, K., Lee, V. M. et al. (1998). Aggregation of $\alpha$-synuclein in Lewy bodies of sporadic Parkinson's disease and dementia with Lewy bodies. Am. J. Pathol. 152, 879-884.

3. Spillantini, M. G., Schmidt, M. L., Lee, V. M., Trojanowski, J. Q., Jakes, R. \& Goedert, M. (1997). $\alpha$-Synuclein in Lewy bodies. Nature, 388, 839-840.

4. Lucking, C. B. \& Brice, A. (2000). $\alpha$-Synuclein and Parkinson's disease. Cell. Mol. Life Sci. 57, 1894-1908.

5. Goedert, M. (2001). $\alpha$-Synuclein and neurodegenerative diseases. Nature Rev. Neurosci. 2, 492-501.

6. Maries, E., Dass, B., Collier, T. J., Kordower, J. H. \& Steece-Collier, K. (2003). The role of $\alpha$-synuclein in Parkinson's disease: insights from animal models. Nature Rev. Neurosci. 4, 727-738.

7. Weinreb, P. H., Zhen, W., Poon, A. W., Conway, K. A. \& Lansbury, P. T., Jr (1996). NACP, a protein implicated in Alzheimer's disease and learning, is natively unfolded. Biochemistry, 35, 13709-13715.

8. Uversky, V. N. (2002). Natively unfolded proteins: a point where biology waits for physics. Protein Sci. 11, 739-756.

9. Dunker, A. K., Lawson, J. D., Brown, C. J., Williams, R. M., Romero, P., Oh, J. S. et al. (2001). Intrinsically disordered protein. J. Mol. Graph. Model. 19, 26-59.

10. Uversky, V. N. (2002). What does it mean to be natively unfolded? Eur. J. Biochem. 269, 2-12.

11. Fernandez, C. O., Hoyer, W., Zweckstetter, M., JaresErijman, E. A., Subramaniam, V., Griesinger, C. \& 
Jovin, T. M. (2004). NMR of $\alpha$-synuclein-polyamine complexes elucidates the mechanism and kinetics of induced aggregation. EMBO J. 23, 2039-2046.

12. Hoyer, W., Cherny, D., Subramanian, V. \& Jovin, T. M. (2004). Impact of the acidic C-terminal region comprising amino acids 109-140 on $\alpha$-synuclein aggregation in vitro. Biochemistry, in the press.

13. Dyson, H. J. \& Wright, P. E. (2002). Coupling of folding and binding for unstructured proteins. Curr. Opin. Struct. Biol. 12, 54-60.

14. Radivojac, P., Obradovic, Z., Smith, D. K., Zhu, G., Vucetic, S., Brown, C. J. et al. (2004). Protein flexibility and intrinsic disorder. Protein Sci. 13, 71-80.

15. Tompa, P. (2002). Intrinsically unstructured proteins. Trends Biochem. Sci. 27, 527-533.

16. Dobson, C. M. (2003). Protein folding and misfolding. Nature, 426, 884-890.

17. Serpell, L. C., Berriman, J., Jakes, R., Goedert, M. \& Crowther, R. A. (2000). Fiber diffraction of synthetic $\alpha$-synuclein filaments shows amyloid-like cross- $\beta$ conformation. Proc. Natl Acad. Sci. USA, 97, 4897-4902.

18. Der-Sarkissian, A., Jao, C. C., Chen, J. \& Langen, R. (2003). Structural organization of $\alpha$-synuclein fibrils studied by site-directed spin labeling. J. Biol. Chem. 278, 37530-37535.

19. Conway, K. A., Harper, J. D. \& Lansbury, P. T., Jr (2000). Fibrils formed in vitro from $\alpha$-synuclein and two mutant forms linked to Parkinson's disease are typical amyloid. Biochemistry, 39, 2552-2563.

20. Giasson, B. I., Uryu, K., Trojanowski, J. Q. \& Lee, V. M. (1999). Mutant and wild type human $\alpha$-synucleins assemble into elongated filaments with distinct morphologies in vitro. J. Biol. Chem. 274, 7619-7622.

21. Hashimoto, M., Hsu, L. J., Sisk, A., Xia, Y., Takeda, A., Sundsmo, M. \& Masliah, E. (1998). Human recombinant NACP / $\alpha$-synuclein is aggregated and fibrillated in vitro: relevance for Lewy body disease. Brain Res. 799, 301-306.

22. Caughey, B. \& Lansbury, P. T. (2003). Protofibrils, pores, fibrils, and neurodegeneration: separating the responsible protein aggregates from the innocent bystanders. Annu. Rev. Neurosci. 26, 267-298.

23. Serpell, L. C. (2000). Alzheimer's amyloid fibrils: structure and assembly. Biochim. Biophys. Acta, 1502, 16-30.

24. Uversky, V. N., Li, J. \& Fink, A. L. (2001). Metaltriggered structural transformations, aggregation, and fibrillation of human $\alpha$-synuclein. A possible molecular link between Parkinson's disease and heavy metal exposure. J. Biol. Chem. 276, 44284-44296.

25. Hoyer, W., Antony, T., Cherny, D., Heim, G., Jovin, T. M. \& Subramaniam, V. (2002). Dependence of $\alpha$-synuclein aggregate morphology on solution conditions. J. Mol. Biol. 322, 383-393.

26. Ding, T. T., Lee, S. J., Rochet, J. C., Lansbury, P. T., Jr et al. (2002). Annular $\alpha$-synuclein protofibrils are produced when spherical protofibrils are incubated in solution or bound to brain-derived membranes. Biochemistry, 41, 10209-10217.

27. Conway, K. A., Harper, J. D. \& Lansbury, P. T. (1998). Accelerated in vitro fibril formation by a mutant $\alpha$-synuclein linked to early-onset Parkinson disease. Nature Med. 4, 1318-1320.

28. Conway, K. A., Lee, S. J., Rochet, J. C., Ding, T. T., Williamson, R. E. \& Lansbury, P. T. (2000). Acceleration of oligomerization, not fibrillization, is a shared property of both $\alpha$-synuclein mutations linked to early-onset Parkinson's disease: Implications for pathogenesis and therapy. Proc. Natl Acad. Sci. USA, 97, 571-576.

29. Hoyer, W., Cherny, D., Subramaniam, V. \& Jovin, T. M. (2004). Rapid self-assembly of a-synuclein observed by in situ atomic force microscopy. J. Mol. Biol. 340, 127-139.

30. Lashuel, H. A., Petre, B. M., Wall, J., Simon, M., Nowak, R. J., Walz, T. \& Lansbury, P. T., Jr (2002). $\alpha$-synuclein, especially the Parkinson's diseaseassociated mutants, forms pore-like annular and tubular protofibrils. J. Mol. Biol. 322, 1089-1102.

31. Malisauskas, M., Zamotin, V., Jass, J., Noppe, W., Dobson, C. M. \& Morozova-Roche, L. A. (2003). Amyloid protofilaments from the calcium-binding protein equine lysozyme: formation of ring and linear structures depends on $\mathrm{pH}$ and metal ion concentration. J. Mol. Biol. 330, 879-890.

32. Cohlberg, J. A., Li, J., Uversky, V. N. \& Fink, A. L. (2002). Heparin and other glycosaminoglycans stimulate the formation of amyloid fibrils from $\alpha$-synuclein in vitro. Biochemistry, 41, 1502-1511.

33. Manning-Bog, A. B., McCormack, A. L., Li, J., Uversky, V. N., Fink, A. L. \& Di Monte, D. A. (2002). The herbicide paraquat causes up-regulation and aggregation of $\alpha$-synuclein in mice: paraquat and a-synuclein. J. Biol. Chem. 277, 1641-1644.

34. Necula, M., Chirita, C. N. \& Kuret, J. (2003). Rapid anionic micelle-mediated $\alpha$-synuclein fibrillization in vitro. J. Biol. Chem. 23, 23.

35. Antony, T., Hoyer, W., Cherny, D., Heim, G., Jovin, T. M. \& Subramaniam, V. (2003). Cellular polyamines promote the aggregation of $\alpha$-synuclein. J. Biol. Chem. 278, 3235-3240.

36. Goers, J., Uversky, V. N. \& Fink, A. L. (2003). Polycation-induced oligomerization and accelerated fibrillation of human $\alpha$-synuclein in vitro. Protein Sci. 12, 702-707.

37. Ahn, B. W., Song, D. U., Jung, Y. D., Chay, K. O., Chung, M. A., Yang, S. Y. \& Shin, B. A. (2000). Detection of $\beta$-amyloid peptide aggregation using DNA electrophoresis. Anal. Biochem. 284, 401-405.

38. Jang, J. H. \& Surh, Y. J. (2002). $\beta$-Amyloid induces oxidative DNA damage and cell death through activation of c-Jun $\mathrm{N}$ terminal kinase. Ann. $N$ Y Acad. Sci. 973, 228-236.

39. Kampers, T., Friedhoff, P., Biernat, J., Mandelkow, E. M. \& Mandelkow, E. (1996). RNA stimulates aggregation of microtubule-associated protein tau into Alzheimer-like paired helical filaments. FEBS Letters, 399, 344-349.

40. Nandi, P. K., Leclerc, E., Nicole, J. C. \& Takahashi, M. (2002). DNA-induced partial unfolding of prion protein leads to its polymerisation to amyloid. J. Mol. Biol. 322, 153-161.

41. Nandi, P. K. \& Leclerc, E. (1999). Polymerization of murine recombinant prion protein in nucleic acid solution. Arch. Virol. 144, 1751-1763.

42. Nandi, P. K. (1998). Polymerization of human prion peptide HuPrP 106-126 to amyloid in nucleic acid solution. Arch. Virol. 143, 1251-1263.

43. Cordeiro, Y., Machado, F., Juliano, L., Juliano, M. A., Brentani, R. R., Foguel, D. \& Silva, J. L. (2001). DNA converts cellular prion protein into the $\beta$-sheet conformation and inhibits prion peptide aggregation. J. Biol. Chem. 276, 49400-49409.

44. Gabus, C., Auxilien, S., Pechoux, C., Dormont, D., Swietnicki, W., Morillas, M. et al. (2001). The prion 
protein has DNA strand transfer properties similar to retroviral nucleocapsid protein. J. Mol. Biol. 307, 1011-1021.

45. Gabus, C., Derrington, E., Leblanc, P., Chnaiderman, J., Dormont, D., Swietnicki, W. et al. (2001). The prion protein has RNA binding and chaperoning properties characteristic of nucleocapsid protein NCp7 of HIV-1. J. Biol. Chem. 276, 19301-19309.

46. Canete, M., Villanueva, A., Juarranz, A. \& Stockert, J. C. (1987). A study of interaction of thioflavine T with DNA: evidence for intercalation. Cell. Mol. Biol. 33, 191-199.

47. Kruger, R., Kuhn, W., Muller, T., Woitalla, D., Graeber, M., Kosel, S. et al. (1998). Ala30Pro mutation in the gene encoding $\alpha$-synuclein in Parkinson's disease. Nature Genet. 18, 106-108.

48. Polymeropoulos, M. H., Lavedan, C., Leroy, E., Ide, S. E., Dehejia, A., Dutra, A. et al. (1997). Mutation in the $\alpha$-synuclein gene identified in families with Parkinson's disease. Science, 276, 2045-2047.

49. Krishnan, S., Chi, E. Y., Wood, S. J., Kendrick, B. S., Li, C., Garzon-Rodriguez, W. et al. (2003). Oxidative dimer formation is the critical rate-limiting step for Parkinson's disease $\alpha$-synuclein fibrillogenesis. Biochemistry, 42, 829-837.

50. Tateno, M., Yamasaki, K., Amano, N., Kakinuma, J., Koike, H., Allen, M. D. \& Suzuki, M. (1997). DNA recognition by $\beta$-sheets. Biopolymers, 44, 335-359.

51. Crowther, R. A., Daniel, S. E. \& Goedert, M. (2000). Characterisation of isolated $\alpha$-synuclein filaments from substantia nigra of Parkinson's disease brain. Neurosci. Letters, 292, 128-130.
52. Dev, K. K., Hofele, K., Barbieri, S., Buchman, V. L. \& van der Putten, H. (2003). Part II: $\alpha$-synuclein and its molecular pathophysiological role in neurodegenerative disease. Neuropharmacology, 45, 14-44.

53. Lin, W. L., DeLucia, M. W. \& Dickson, D. W. (2004). $\alpha$-Synuclein immunoreactivity in neuronal nuclear inclusions and neurites in multiple system atrophy. Neurosci. Letters, 354, 99-102.

54. Goers, J., Manning-Bog, A. B., McCormack, A. L., Millett, I. S., Doniach, S., Di Monte, D. A. et al. (2003). Nuclear localization of $\alpha$-synuclein and its interaction with histones. Biochemistry, 42, 8465-8471.

55. Shibayama-Imazu, T., Okahashi, I., Omata, K., Nakajo, S., Ochiai, H., Nakai, Y. et al. (1993). Cell and tissue distribution and developmental change of neuron specific $14 \mathrm{kDa}$ protein (phosphoneuroprotein 14). Brain Res. 622, 17-25.

56. Khurana, R., Ionescu-Zanetti, C., Pope, M., Li, J., Nielson, L., Ramirez-Alvarado, M. et al. (2003). A general model for amyloid fibril assembly based on morphological studies using atomic force microscopy. Biophys. J. 85, 1135-1144.

57. Wood, S. J., Wypych, J., Steavenson, S., Louis, J. C., Citron, M. \& Biere, A. L. (1999). $\alpha$-synuclein fibrillogenesis is nucleation-dependent. Implications for the pathogenesis of Parkinson's disease. J. Biol. Chem. 274, 19509-19512.

58. Cherny, D. I., Striker, G., Subramaniam, V., Jett, S. D., Palecek, E. \& Jovin, T. M. (1999). DNA bending due to specific p53 and p53 core domain-DNA interactions visualized by electron microscopy. J. Mol. Biol. 294, 1015-1026.

Edited by M. Yaniv

(Received 29 March 2004; received in revised form 27 August 2004; accepted 30 September 2004) 